\title{
A eletricidade entra em cena
}

\section{Electricity enters the stage}

Cibele Forjaz Simões ${ }^{1}$ 


\section{Resumo}

Este artigo faz um levantamento histórico das primeiras pesquisas e aplicações práticas da energia elétrica no teatro, primordialmente a partir da invenção das lâmpadas de arco-voltaico (1849) e incandescente (1879), para analisar as mudanças que a energia elétrica possibilita para a arte do espetáculo, em sua relação com o surgimento da encenação. O eixo central é a transformação da função da iluminação cênica, de instrumento da visibilidade a elemento estrutural e estruturante da escrita cênica, constituindo-se como linguagem.

Palavras-chave: Iluminação cênica; história e estética da iluminação cênica; linguagem da iluminação cênica

\section{Abstract}

This article surveys the history of the first researches and practical applications of electricity in theater, mainly since the invention of the arc-voltaic lamp (1849) and the incandescent light (1879), so as to analyze the changes electric energy made possible to the art of spectacle and its relationship to the beginning of staging. The central argument is about the transformation of scenic lighting's function from an instrument of visibility to a structural element of scenic writing, a structuring element that constitutes itself as a language.

Keywords: Scenic lighting; history and aesthetics of scenic lighting; language of scenic lighting

ISSN: 1414.5731

E-ISSN: 2358.6958

${ }^{1}$ Profa. Dra. Departamento de Artes Cênicas - Escola de Comunicação e Artes (ECA) - Universidade de São Paulo (USP). Atuando na graduação e no Programa de Pós-Graduação em Artes Cênicas (PPGAC/ECA/USP). Diretora e iluminadora teatral. cibeleforjaz@gmail.com 
A luz elétrica não foi descoberta de repente, como uma ideia brilhante ou uma iluminação divina, conforme nos conta a mística das invenções: Thomas Edison vê um raio no céu e acende uma lâmpada na cabeça do gênio, estava descoberto o "princípio da luz elétrica". Ou então, como é comum ver descrito em manuais de iluminação: Thomas Edison inventa a lâmpada incandescente em 1879 e em 1880, como por mágica, os teatros começam a usar a "luz elétrica".2

Ao contrário, a entrada da luz gerada pela energia elétrica em cena é um processo longo de experimentação das chamadas "ciências físicas" nas artes do espetáculo, principalmente nas grandes casas de ópera europeias, durante todo o século XIX, com o objetivo de criar grandes efeitos especiais. A pesquisa e aplicação prática da energia elétrica no teatro culmina com a utilização de duas tecnologias diferentes na iluminação cênica: a lâmpada de arco-voltaico (usada nos teatros desde 1849) e a lâmpada incandescente (desde 1879).

A primeira experiência pública com o arco-voltaico - transmissão de elétrons pelo ar entre dois polos com diferentes voltagens, criando um "arco de luz" (mesmo princípio do raio) - data de 1808, na Inglaterra³. Em 1841 o físico Leon Foucault usou o mesmo princípio para substituir a fonte de luz em um microscópio solar. A primeira demonstração pública do projetor a arco-voltaico, inventado por ele, aconteceu em Paris, na Place de la Concorde, em uma noite no fim de 1842 , em um verdadeiro espetáculo público de luz.

Este aparelho, por sua vez, foi aperfeiçoado pelo óptico Jules Duboscq (18171886), que acrescentou um refletor parabólico ao conjunto e criou, segundo suas próprias palavras: "uma das primeiras aplicações da ciência no teatro, isto é o emprego da luz elétrica" (Duboscq, 1983, p. 358).

A lâmpada de arco voltaico estreia no palco, enfim, em 1849, na ópera Profeta, de Meyerbeer e seu primeiro papel foi, significativamente, representar o sol nascente. Sobre essa estreia da eletricidade no teatro, comenta Denis Bablet em seu artigo $A$ Luz no Teatro:

Esse primeiro emprego da eletricidade adquire o valor de um símbolo: tratava-se da imitação de um fenômeno natural e de um efeito destinado a maravilhar o espectador. Durante perto de cinquenta anos não se atribuirá outro papel à luz elétrica. (Bablet, 1964, p. 291)

Nos anos seguintes, o mesmo efeito foi replicado em várias óperas. Todas as grandes casas de Ópera da Europa passaram a ter os seus "mestres dos fenômenos físicos no teatro", "chefes de eletricistas" e "especialistas em óptica". Os novos criadores de máquinas cênicas não são mais os arquitetos ou pintores, são agora os "cientistas-iluminadores", como Jules Duboscq, criadores dos grandes efeitos especiais das óperas de seu tempo. Esses "mestres dos fenômenos físicos no teatro" são antepassados diretos dos iluminadores.

\footnotetext{
2 É comum ler erros crassos em manuais de iluminação como, por exemplo, que a luz elétrica chega ao teatro a partir da descoberta da lâmpada incandescente, ou, até mesmo, que a luz elétrica foi inventada em 1879 porque, na minha opinião, há uma mistura entre lâmpada incandescente com lâmpada elétrica e em pouco tempo, Thomas Edison parece ter inventado a luz elétrica, o que não é verdade.

3 "... a carbon arc (first demonstrated by Sir Humphry Davy in 1808)". Streader, Tim e Williams, John A. Create Your Own Stage Lighting. New Jersey: Prentice Hall Inc., 1985, p. 16. (Tradução nossa)
} 
A seguir, reproduziremos alguns desenhos, acompanhados de pequenas descrições de cada um desses "aparelhos luminotécnicos", do próprio "Catálogo dos aparelhos utilizados na produção de fenômenos físicos no teatro, por Jules Duboscq, óptico chefe do serviço de iluminação elétrica na Ópera de Paris" (Duboscq, 1983, p. 357), para termos a dimensão da tecnologia dos projetores com lâmpada a arco-voltaico e de seus empregos, quarenta anos antes da invenção da lâmpada incandescente.

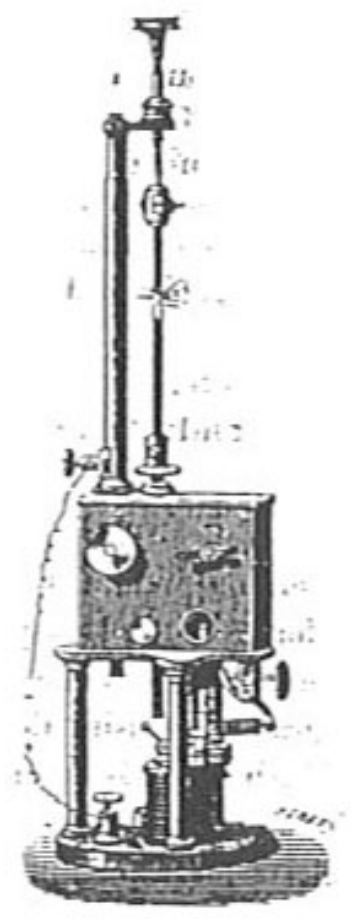

Figura 1 - Lâmpada de Arco-voltaico - 1849 Fonte: Duboscq, 1983, p. 357

Figura 2 - Aparelho destinado a produzir o efeito do Sol levantando 1849 (De O Profeta) Fonte: Duboscq, 1983, p. 357

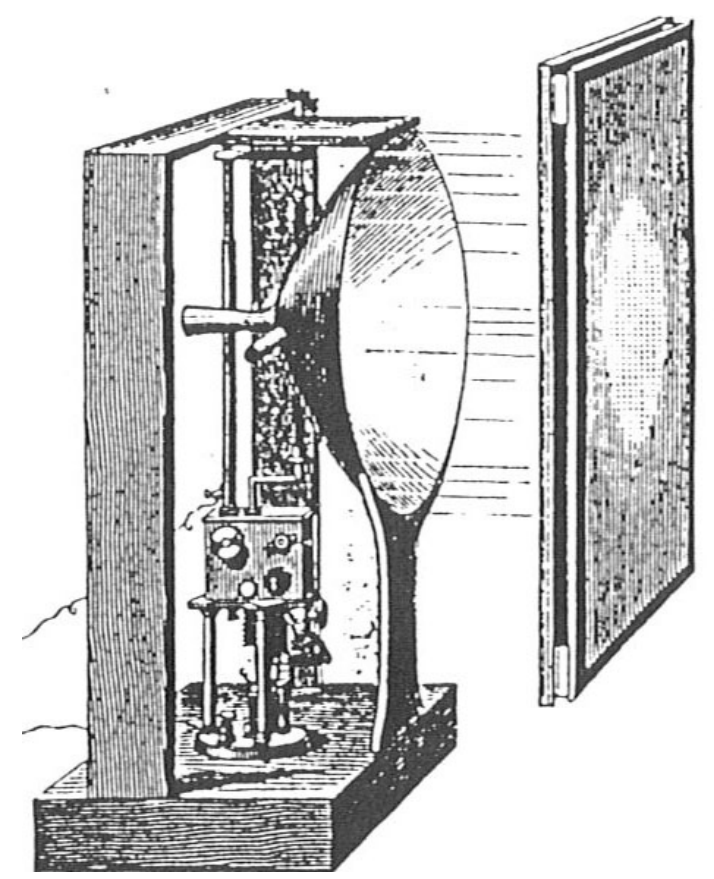




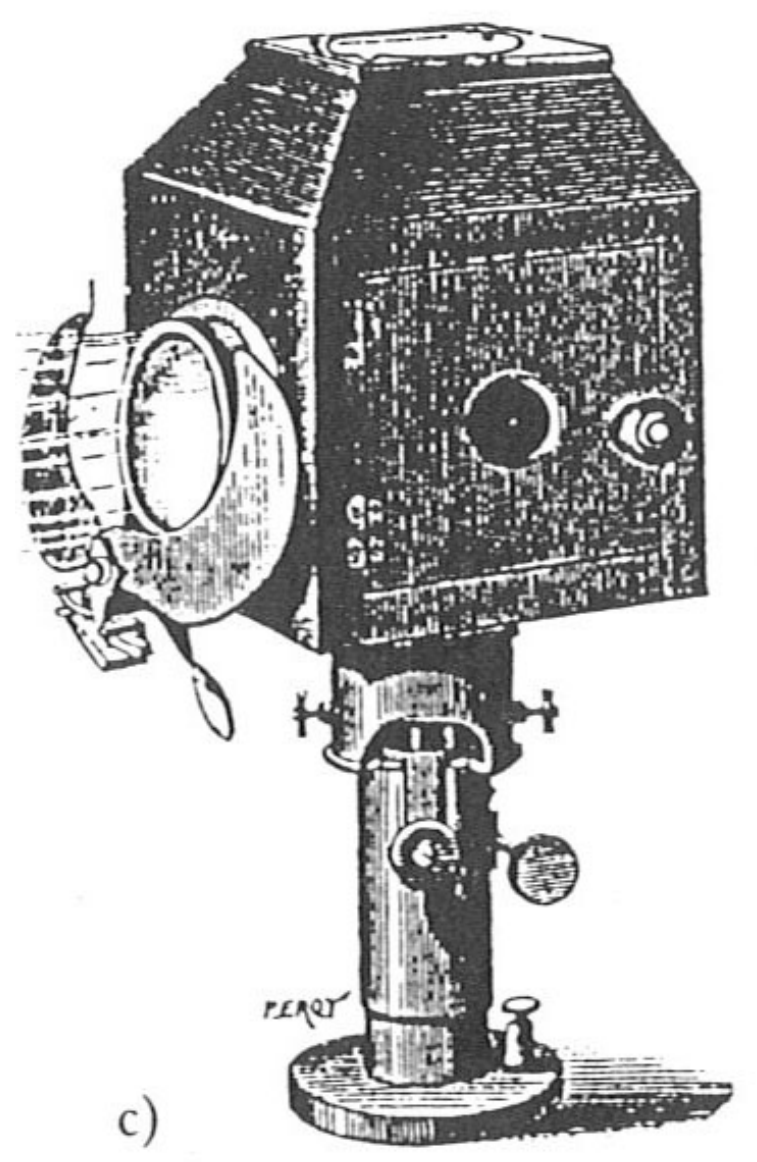

Figura 4 - Aparelho para produzir o "fenômeno do arco-íris" (1860). Fonte: Duboscq, 1983, p. 357
Figura 3 - Aparelho fotoelétrico com sua lâmpada, destinado a perseguir um personagem, que permite dirigir os raios luminosos para todos os sentidos (1860). Fonte: Duboscq, 1983, p. 357

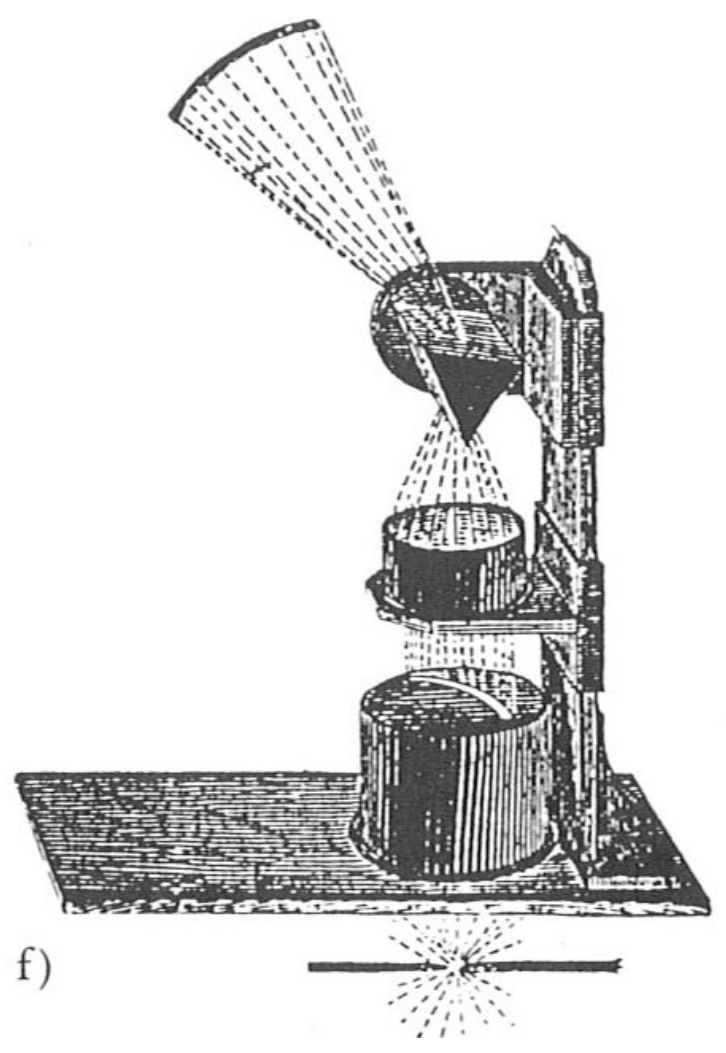




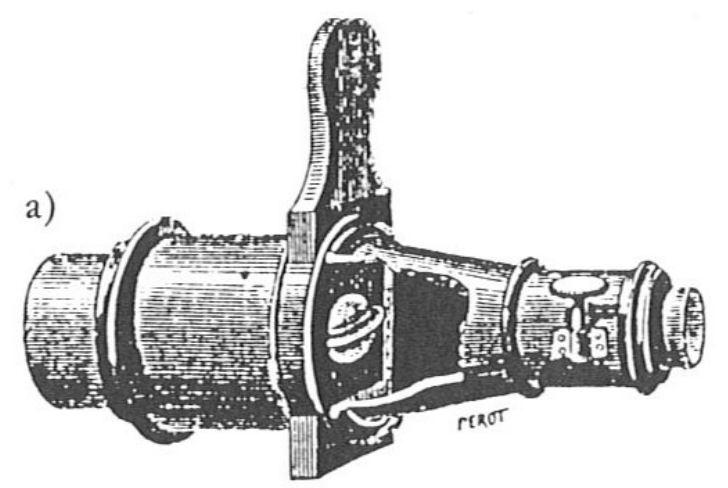

Figura 5 - Primeiro aparelho para projeção de imagens reais para "ampliação de provas fotográficas sobre vidro" (1864) Fonte: Duboscq, 1983, p. 357

Embora a iluminação principal tenha permanecido a gás, na grande maioria dos teatros, na segunda metade do século XVIII, a eletricidade já faz parte da tecnologia das casas de Ópera de toda a Europa, quase sempre no papel de "efeito especial" para impressionar a plateia, como descreve o próprio Jules Duboscq, em seu Catálogo de 1864:

Tornou-se raro que um balé ou uma ópera, que exijam uma encenação importante, tenham sido apresentados sem a intervenção de um efeito qualquer da luz elétrica [...]. Os teatros imperiais e aqueles de primeira ordem seguem sob o impulso da ópera; e o arco-voltaico passa definitivamente aos costumes cênicos". (Duboscq, 1983, p. 358)

Como pudemos perceber pelos desenhos técnicos, além dos aparelhos idealizados para realizar "fenômenos físicos" que imitam os fenômenos da natureza como o Sol nascente e o arco-íris, existe um "projetor de perseguir", ou seja, um "canhão seguidor". A descrição do primeiro uso desses projetores em Moisés, apresentado na Ópera de Paris, em 1860, relata suas atribuições:

$\mathrm{Na}$ entrada da personagem principal, púnhamos sobre ela uma lâmpada de raio concentrado, articulado, que a seguia nos seus deslocamentos; dois outros projetores atrás dos cantos jogavam seus raios sobre a tenda no meio da cena; uma terceira lâmpada, no primeiro plano, iluminava igualmente na direção da sua tenda...". (Duboscq, 1983, p. 362)

Ou seja, na segunda metade do século XIX já temos em cena, na ópera, projetores elétricos com lâmpada de arco-voltaico, fonte individualizada, sistema ótico e articulações para movimento, que viabilizam um desenho de luz móvel, com o objetivo de destacar personagens e partes do cenário.

O último aparelho que comentaremos aqui é um projetor de imagens para criar "aparições fantásticas" (Duboscq, 1983, p. 359). Ele funciona projetando e ampliando imagens pintadas (ou impressas por meio fotográfico) em vidro. Segundo uma descrição de Jules Duboscq, ele tentou criar movimento a partir de uma sequência de imagens projetadas, porém não conseguiu o efeito desejado. Mas seus aparelhos pioneiros foram aperfeiçoados em Dresden, na Alemanha, por um mestre da luz, Hugo Bähr, que conseguiu criar a tão sonhada "sensação de movimento".

Hugo Bähr é considerado pelos alemães como o "pai da luz". Filho de um pintor de vidro que trabalhava na confecção de desenhos e pinturas nas "lanternas mági- 
cas", começou a trabalhar no teatro com as projeções à la Duboscq. Apaixonado pela técnica das lanternas mágicas, inventou uma forma de criar movimento na projeção, utilizando-se do poder motor da eletricidade, a partir do movimento da própria imagem que está sendo projetada: como, por exemplo, as imagens de nuvem que rodam na frente do sistema óptico de um refletor ou os reflexos de chuva, com imagens trepidantes. Autor de "aparelhos eletro-ópticos para a realização de efeitos luminosos e de aparição no teatro" (Bähr, 1983, p. 364), ficou famoso em toda a Europa. Criava máquinas específicas sob encomenda, verdadeiras "traquitanas cênicas" luminosas, para os difíceis efeitos especiais que as grandes casas de ópera demandavam. Inventou centenas de efeitos diferentes, como os movimentos de luz e projeção dos Meininger ${ }^{4}$ e os efeitos especiais das grandes óperas de Richard Wagner (1813-1883).

Em 1876, Wagner estreia o Festspielhaus na Bayreuth: um teatro tecnicamente construído especialmente para criar ilusão, através dos sentidos. Para isso, inventa grandes inovações técnicas: em primeiro lugar, propõe uma reviravolta no ponto de vista da relação entre espectador e obra ao apagar a luz da plateia. Deste modo, com a orquestra escondida da visão, a música envolve o público e os olhos mergulham (sem nenhuma barreira ofuscante ou qualquer outro ponto de referência) dentro da cena, inteiramente iluminada por refletores de arco-voltaico e com as "aparições" das Walkírias projetadas, com uma sequência de movimentos realizados por Hugo Bähr, graças a uma traquitana elétrica com vidros pintados movendo-se na frente da lente do "projetor de imagens". Provavelmente chegamos aí, aos píncaros do grande efeito da "ilusão teatral" das óperas do século XIX e, portanto, também, a um ponto de virada.

Essas experiências marcam a passagem da luz criada principalmente pelos cenógrafos, seguindo uma tradição vinda da Renascença, para uma luz criada e realizada por profissionais específicos, cientistas-inventores, mestres de ofício da luminotécnica, visando desenvolvimentos fundamentalmente técnicos que articulam a eletricidade, a física e a óptica para criar os primeiros aparelhos de projeção de luz e imagens.

Este fato marca, também, o início de uma transição lenta (que vai até, aproximadamente, a primeira metade do século $\mathrm{XX}$ ) entre uma iluminação realizada primordialmente com aparelhos de luz aberta, com várias fontes (como as ribaltas, gambiarras e "tangões"), que iluminam grandes áreas indistintamente e os refletores com uma única fonte de luz e sistema óptico, herdeiros desses aparelhos de Jules Dusboucq e Hugo Bähr, como os refletores especializados que utilizamos hoje.

Todas estas experiências de iluminação elétrica, antes de 1879, mostram múltiplos caminhos de desenvolvimento técnico e destroem uma versão corrente que quer fazer crer que a lâmpada incandescente de Thomas Edison é uma espécie de "Fiat Lux" da história da iluminação e não uma parte, importantíssima, de um processo técnico e artístico que tem muitas transformações e reviravoltas.

Existe um longo caminho entre a pesquisa e as invenções e sua transformação em ciência aplicada, principalmente no que concerne aos meios de produção e da

\footnotetext{
4 "A partir de 1874, a companhia dos Meininger fornece à Alemanha e depois a toda a Europa o exemplo de um conjunto no qual o diretor (o Duque George II Von Meiningen em pessoa) e seu encenador (Chronegk) comandam os atores. E seus espetáculos são concebidos, cada um, como um todo orgânico". (Dort, 1977, p.83).
} 
generalização de uma nova tecnologia. Muitos homens no século XIX usaram a eletricidade para gerar energia luminosa, vários deles colocaram-na em prática. Muitas pesquisas científicas procuravam a energia luminosa através da incandescência gerada pela energia elétrica, alguns chegaram mesmo a inventar outras formas de lâmpadas incandescentes, na mesma época que Edison, em lugares diferentes ${ }^{5}$.

Mas em 1879, o americano Thomas Edison não somente inventa uma lâmpada incandescente de filamento de carbono, como começa a produzi-la em escala de mercado, tornando-a economicamente viável. A partir de então, o emprego da eletricidade generaliza-se como forma de iluminação em casas, lojas, fábricas e, com impressionante rapidez, nos teatros. No mesmo ano de 1879 o Teatro da Califórnia utiliza as lâmpadas incandescentes produzidas pela Edison Electric \& Co. e em 1881 o Teatro Savoy, de Londres, já era totalmente iluminado pela eletricidade. ${ }^{6}$

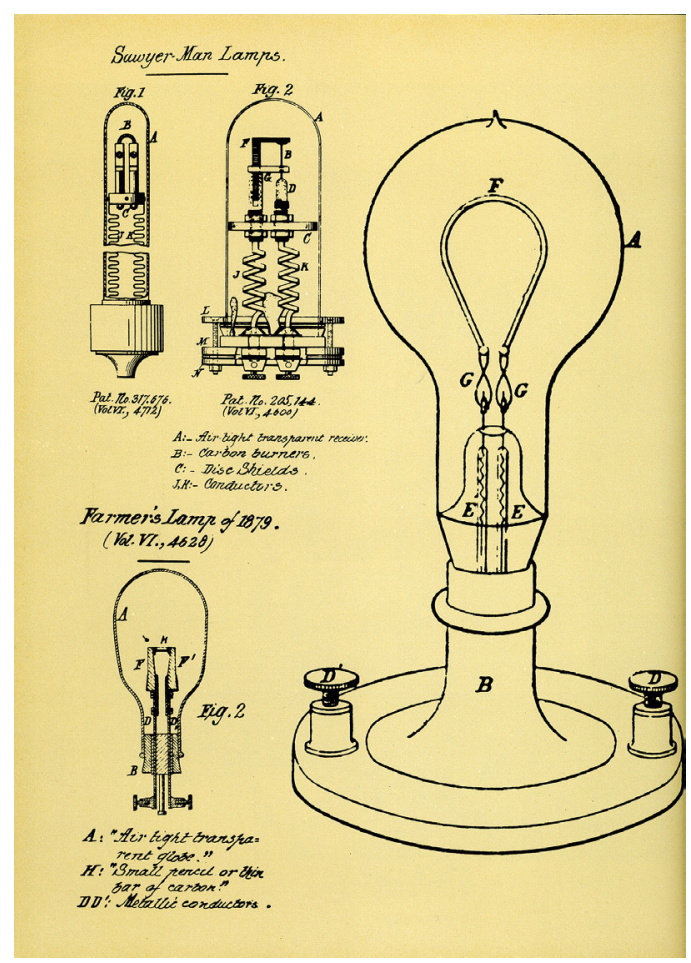

Figura 6 - Desenho da lâmpada de Thomas Edison.

COX, James A. A Century of Light. USA: A Benjamin Company and Rutledge Books, 1978.

Enquanto a instalação dos sistemas a gás demorou em torno de cinquenta anos, a troca destes pela energia elétrica acontece, em larga escala, em apenas uma década, entre 1880 e 1890, atestando a aceitação da novidade e a sua eficiência técnica e econômica7.

\footnotetext{
5 "Durante o século XIX, um grande número de inventores trabalhou nas lâmpadas incandescentes. Em 1891, o governo britânico registrou a patente para Frederick De Moeyns. Nesta mesma época, o engenheiro inglês J.W. Starr patenteou a lâmpada da Starr-King, com filamento de carvão. Sir Joseph W. Swan desenvolveu uma série de lâmpadas, entre 1848 e 1860". Saraiva, Hamilton F. Iluminação Teatral: História, Estética e Técnica. Dissertação de Mestrado. São Paulo: ECA/USP, 1990, p.61.

6 "Este teatro é iluminado totalmente pela eletricidade; é a frase que consta no programa do Teatro Savoy de Londres em 1881 e é notável dizer-se que se usaram também resistências (seis ao todo) montadas pela firma Irmãos Siemens". Frederick Benthan, The Art os Stage Lighting. Londres: Pitman Pub., s/d, p.37. 7 "De 1880 a 1890, os principais teatros europeus adoptam-na". (Bablet, 1964, p. 291)
} 
A multiplicação das fontes de luz, a invenção de aparelhos de iluminação cada vez mais especializados para fazer diferentes usos ópticos das fontes de luz, a relação entre as várias fontes e aparelhos, o controle conjunto e a orquestração deste novo arsenal, até a pouco desconhecido, não foi tarefa fácil para eletricistas, ópticos, cenógrafos e diretores que enfrentaram de frente esse desafio - desenvolver a iluminação teatral móvel. Na fronteira entre a técnica e a estética, a iluminação teatral passou a envolver uma aplicação prática diária no teatro das ciências da física, da óptica, da geometria, da eletricidade e da eletrônica.

No entanto, a mudança da função da iluminação cênica não se deu simplesmente pela mudança técnica que representa a utilização da luz elétrica. Ainda seria preciso mudar o paradigma do teatro para que a luz deixasse de ser pensada e utilizada unicamente como instrumento da visibilidade ou efeito especial da ciência para arrebatar suspiros.

\section{A reviravolta ou a luz elétrica e o surgimento da linguagem da iluminação cênica}

Como vimos, a estreia da luz elétrica no teatro, por si só, não revelou a real dimensão do significado desta nova tecnologia para a história do espetáculo. As lâmpadas incandescentes utilizadas a partir dos anos 1880, foram consideradas primeiramente apenas como uma nova técnica, mais eficiente, para realizar as mesmas funções: clarear a cena e copiar, com maior verossimilhança, os efeitos da natureza, como o arco-íris ou o pôr do sol:

Trata-se, portanto, de começo, de simples técnica de substituição: os aparelhos de iluminação elétrica substituem, pura e simplesmente, os aparelhos de gás, cujos lugares ocupam. Não se descortinam ainda os seus poderes, não se adivinha que a luz elétrica possa tornar-se um meio de expressão dramática: reconhecida como um inegável progresso técnico continua a ser um fator puramente descritivo. Nem podia ser doutra maneira numa época em que tudo na encenação, representação do comediante, cenário, figurinos, iluminação, tem de reproduzir fielmente a natureza. (Bablet, 1964, p. 292)

As resistências regulam as intensidades das lâmpadas incandescentes e, portanto, permitem o controle total do movimento da luz. Porém não pareceria coerente para o teatro realista dos anos 1880 que a luz se movesse no meio da ação, chamando atenção para sua existência fictícia ou criando uma transformação artificial de tempo ou espaço. Na natureza, o movimento da luz do Sol é contínuo. Não muda de acordo com o que acontece na terra, não escurece quando uma tragédia se anuncia, não brilha mais nos momentos de prosperidade e alegria, não dá saltos, nem surpreende; apenas determina, com seu aparente movimento lento e gradual, os dias e as noites; o que para nós, mortais, indica o passar do tempo - inexorável e incontrolável.

Segundo Denis Bablet, essa característica meramente descritiva da luz no século XIX, própria de um teatro onde a realidade e a coerência são a medida de todas as coisas, tem como único resultado possível uma iluminação que não intervém na 
ação e não desempenha qualquer papel ativo na construção do espetáculo, ou seja, uma luz passiva ${ }^{8}$.

Porém a potência da nova tecnologia, principalmente no que concerne ao movimento da luz, estava ali, latente.

Será o encontro entre as possibilidades da iluminação elétrica com as necessidades da cena advindas de novas teorias e práticas do teatro, que transformará potência em ato, impulsionando o salto qualitativo da iluminação cênica, rumo às formas do teatro moderno.

Seria mais exato, sem dúvida, dizer que essas transformações se concretizaram graças à coexistência de um desejo de ruptura e de uma possibilidade de mudança. Em outras palavras, as condições para uma transformação da arte cênica achavam-se reunidas, porque estavam reunidos, por um lado, o instrumento intelectual (a recusa das teorias e fórmulas superadas, bem como propostas concretas que levavam à realização de outra coisa) e a ferramenta técnica que tornava viável uma revolução desse alcance: a descoberta da iluminação elétrica. (Roubine, 1996, p. 22)

Jean-Jacques Roubine é incisivo ao nomear a descoberta dos novos recursos da iluminação elétrica como fator tecnológico fundamental para o surgimento da encenação:

Nos últimos anos do século XIX ocorreram dois fenômenos, ambos resultantes da revolução tecnológica, de uma importância decisiva para a evolução do espetáculo teatral, na medida em que contribuíram para aquilo que designamos como o surgimento do encenador. Em primeiro lugar, começou a se apagar a noção das fronteiras e, a seguir, a das distâncias. Em segundo, foram descobertos os recursos da iluminação elétrica. (Roubine, 1996, p. 21)

Esta síntese entre técnica e estética na iluminação cênica será empreendida na passagem do naturalismo para o simbolismo, rumo às vanguardas modernas, através da pesquisa e prática destes encenadores, agentes das grandes transformações do teatro na virada do século XX. Não se trata mais da união "natural e harmônica" entre as artes, como propõe a Gesantkunstwerk wagneriana (Obra de Arte Total), mas de uma concepção, que dirige as diferentes artes que compõem a cena, relacionando-as e transformando-as em outra obra de arte, com uma unidade própria. Essa articulação central das linguagens constitutivas do fenômeno teatral gera maior complexidade na escritura cênica. O texto teatral deixa de ser a medida de todas as coisas, o guia fundamental da cena e o espetáculo vai, pouco a pouco, mostrando diversas facetas e leituras da obra dramatúrgica. ${ }^{9}$ Cada vez mais a interpretação da realidade vai ganhando primazia diante da própria realidade, rumo à subjetividade. E esse sujeito criador se personifica durante o teatro do século $\mathrm{XX}$, principalmente, na figura do diretor, ou encenador:

\footnotetext{
${ }^{8}$ Bablet em seu artigo "A luz no teatro" (1964, p.294) utiliza-se do conceito de luz passiva, contrário à luz ativa, onde a iluminação cênica constitui-se como um elemento consciente na construção do espetáculo.

9 "Toda reflexão sobre o teatro contemporâneo nos conduz ao acontecimento que literalmente fundou este teatro: a diferenciação da encenação enquanto arte autônoma [...] nela introduzindo, em certo sentido, uma nova dimensão: a de uma arte cênica diferente da arte dramática". (Dort, 1977, p.83)
} 
O diretor moveu-se para o centro da plasmação do espetáculo e da crítica teatral. Definia o estilo, moldava os atores, dominava o cada vez mais complexo mecanismo de técnicas cênicas. O palco giratório, o ciclorama, a iluminação policromática estava a sua disposição. Formas de estilo e de jogo teatral seguiram em rápida sucessão dentro de poucas décadas, sobrepondo-se: naturalismo, simbolismo, teatro convencional e teatro liberado, tradição e experimentação, drama épico e do absurdo, teatro mágico e teatro de massa. (Berthold, 2003, p. 452)

Mas é a ruptura com a lógica da realidade que levará à reviravolta da função da luz na história do espetáculo, de uma luz passiva, que segue a lógica fotográfica do espaço e do tempo realistas, para uma luz ativa, que constrói novos espaços e tempos, multiplicando os planos de significação da encenação. O conceito de "luz ativa" foi criado por Adolphe Appia ${ }^{10}$ e refere-se primordialmente ao poder da luz de exprimir com seu movimento a essência da vida do drama, mais especificamente, do drama wagneriano. O conceito de "luz passiva", contrária à "luz ativa", é utilizado por Denis Bablet no artigo A Luz no Teatro (1964, p. 264). Para Bablet, "luz ativa" é aquela que se constitui como um elemento móvel e consciente na construção do espetáculo. Roberto Gill Camargo (2000) desenvolve um conceito análogo ao considerar a luz como actante. De qualquer forma, ambos colocam o foco da transformação da função da luz no espetáculo, na ideia de ação da luz.

A grande diferença da luz elétrica para a luz do fogo não está só na quantidade ou na qualidade da luz, mas no controle das intensidades que ela possibilita, criando o movimento entre a luz e seu oposto complementar, o escuro. Pela primeira vez na história do teatro, havia condições técnicas para, num piscar de olhos, transformar totalmente a cena. A grande novidade da iluminação elétrica, portanto, é a possibilidade da não-luz, que ofuscada pela lâmpada acesa demorará décadas para ser percebida. Além de dar visibilidade, a iluminação cênica ganhou o poder de esconder. Em última instância, a luz elétrica inventou também o escuro no teatro: o Black-out.

O Black-out era a metade que faltava, a pausa, o corte, o silêncio que dá sentido à articulação dessa língua. O contraste originário entre luz e sombra dá forma a nossa percepção do espaço e, desde o princípio dos tempos, o dia e a noite se sucedem marcando a passagem do tempo. Através do movimento entre a luz e a escuridão, com suas miríades de combinações, o teatro acessa além do visível, o invisível; e através dele a sugestão, a comunicação possível daquilo que é indizível.

Com a possibilidade de controlar o caminho da luz para a não-luz, de forma independente em cada um de seus aparelhos de iluminação elétrica, a iluminação cênica ganha a potência de articular o desenho do espaço cênico, para a percepção visual, em uma sucessão temporal. Ou seja, o movimento da luz representa para as artes do espetáculo, a possibilidade infinita de articulação do visível, entre o espaço e o tempo.

Por isso, em seus textos de análise dos vários elementos que compõem a escrita cênica e suas relações, Adolphe Appia transforma efetivamente a função da iluminação de uma luz passiva, que tem por objetivo apenas "tornar visível", para uma luz

\footnotetext{
${ }^{10}$ Appia, Adolphe. La mise en scène du drame wagnérien. In : CEuvres Complètes, Tome I. Paris: L'Âge d'Homme, p. 268 e La Musique et la mise en scène. In : CEuvres Complètes, Tome II, p.95.
} 
ativa e móvel. A iluminação confere, então, movimento à cenografia, ou seja, vivifica o espaço, permitindo uma relação concreta entre o ator vivo e o espaço, tornado vivo através da luz. Para Appia a LUZ ATIVA é o instrumento de orquestração das relações entre os diversos elementos que compõe o espetáculo:

E aqui está nossa hierarquia constituída normalmente:

O Ator, que representa o drama,

O Espaço, com suas três dimensões, a serviço da forma plástica do ator,

A Luz, que vivifica um e outro. ${ }^{11}$

É desta articulação entre espaço e tempo, em movimento, que se constitui a escritura da luz, urdida de diferentes formas no decorrer do século XX, em crescente desenvolvimento tecnológico.

Aqui chegamos a um ponto fundamental, à razão de ser deste artigo. A iluminação cênica passa a ter com a utilização da eletricidade o poder, através do movimento, de desenvolver uma partitura do que é visível em cena, e de como é visível. $E$, portanto, o poder de se transformar em linguagem. Mas o instrumento da mudança não é a mudança. Nem o pincel e as tintas são a pintura. A iluminação cênica não virou linguagem por causa da utilização da luz elétrica no teatro, embora ela tenha dado a ferramenta necessária para isso, assim como a iluminação não é linguagem à priori, só porque usamos de alta tecnologia na projeção de luzes e imagens.

Esse processo de transformação da iluminação cênica em linguagem não aconteceu de um momento para o outro; da descoberta tecnológica à incorporação desta tecnologia no discurso, foi necessário tempo e, sobretudo, o surgimento da arte da encenação, que criou a necessidade e o conceito da luz como verbo do olhar.

A linguagem da encenação moderna criará uma nova função para a iluminação cênica, na medida em que o simbolismo e, na sequência, as vanguardas modernas (expressionismo alemão, construtivismo russo, futurismo italiano, surrealismo, dadaísmo, etc.) libertam a arte da imitação da realidade.

A iluminação, finalmente liberta das amarras da reprodução da realidade, transpõe o visível para criar novas formas, por meio de uma reorganização dos elementos visuais: as linhas, volumes e cores ganham flexibilidade através do movimento da luz em sua relação com a matéria e os olhos. Esse dado libertador será fundamental para que as potencialidades da luz elétrica se transformem em ato nas mãos dos encenadores-iluminadores. Os artistas do espetáculo, de retratistas, tornar-se-ão criadores de outras realidades visuais. É da tensão entre a realidade e a ficção, espelhada em vários níveis e de diferentes formas, que se constituiu grande parte do teatro no século XX.

As vanguardas modernas do começo do século $X X$, por sua vez, empreendem nova revolução conceitual e adotam a teatralidade como forma de construção explícita da cena. O teatro deixa de querer ser realidade para se assumir enquanto teatro e, como tal, poder jogar livre e abertamente com suas linguagens. É só aí que

${ }^{11}$ Appia, Adolphe. L' avenir du drame et de la mise en scène (1919). In: Oeuvres Complètes. Lausanne: Société Suisse du Théâtre/L'Âge d'Homme. Tome III, 1988, p. 336. 
luz deixa de copiar o sol, a lareira e o abajur das casas de família e passa a escrever no espaço e no tempo, como uma linguagem explícita da cena. Além de dar visibilidade, volume, beleza, localização espacial e atmosfera apropriada à peça, a luz passa a ter por função a edição do visível no espaço e no tempo, transformando-se, portanto, em elemento estrutural e estruturante na construção do espetáculo.

Essa revolução não é só estética, não é só técnica, a iluminação cênica é ao mesmo tempo e indissoluvelmente arte e técnica.

Se a descoberta e utilização da eletricidade como energia geradora de aquecimento, iluminação, imagens e movimento transformou nossa existência de tal forma, não é de se esperar que essas mudanças tenham reflexos profundos em nossa maneira de ver e fazer teatro? E tenham também transformado a nossa relação com a ideia de representação e linguagem?

A linguagem é uma possibilidade de articulação, uma potência que depende da necessidade e da prática para se atualizar, assim como o discurso depende do conhecimento da língua e também da necessidade da comunicação que o articula. É por isso que além de falar, o homem necessita compreender a estrutura da fala e as necessidades do discurso. É através deste processo de compreensão e articulação que o som vira língua, a língua vira linguagem, o discurso, obra de arte. Este é um processo da humanidade, mas também é um processo que se reatualiza de forma diferente em cada indivíduo que a compõem, em cada processo de criação.

A cada vez que um espetáculo se articula ele precisa relembrar seu lugar no espaço e no tempo, se entender enquanto linguagem complexa, que articula várias linguagens. Essas linguagens falam juntas ou não, criam harmonias ou confusão, contraponto ou bagunça. Não tem mais sentido entender a iluminação hoje apenas como desenho de luz no espaço, ela é primordialmente escritura no espaço/tempo. O que significa dizer que a luz coloca seus desenhos no tempo, como a música suas harmonias, e através do seu movimento escolhe o que é visível ou não no espetáculo. Nesse sentido é cúmplice fundamental da direção na significação da encenação. Para isso precisa se construir junto com o espetáculo.

As lâmpadas não falam per si. Se não houver por parte do iluminador um conhecimento profundo do texto, do processo de construção da cena e articulação com as diversas linguagens de que é composto o espetáculo, segundo os conceitos daquela encenação específica, as lâmpadas de um teatro valem tanto quanto a lâmpada de uma sala de estar ou de uma vitrine de roupas. O roteiro da iluminação cênica é o texto da luz. E como tal precisa ter consciência do seu poder de articulação. É preciso fazer a língua falar com sentido, para ser de fato linguagem.

Se os profissionais da cena, entre eles os encenadores e os iluminadores não souberem pensar a luz como linguagem estrutural e estruturante da cena contemporânea, ela não o será, assim como não o foi quando a luz elétrica surgiu, simplesmente porque "deu à luz". Daí a importância de pensar o processo de transformação da luz em linguagem na história do teatro, para poder atualizá-lo completamente, aqui e agora. 


\section{Referências}

APPIA, Adolphe. A Obra de Arte Viva. (Trad. Redondo Jr.) Ed. Arcádia, Lisboa, s/d.

APPIA, Adolphe. L' avenir du drame et de la mise en scène (1919). In: Oeuvres Complètes. Lausanne: Société Suisse du Théâtre/L'Âge d'Homme. Tome III, 1988,

APPIA, Adolphe. Oeuvres Complètes. Lausanne: Société Suisse du Théâtre/L'Âge d'Homme. Tome I (1983), Tome II (1986), Tome III (1988, Tome IV (1992).

BABLET, Denis. A Luz no Teatro. In: O Teatro e sua Estética. (org. e trad. Redondo Júnior). Lisboa: Arcádia, 1964.

BABLET, Denis. Esthétique Générale du Décor de Théâtre de 1870 a 1914. Paris: Editions du Centre National de la Recherche Scientifique, 1989.

BABLET-HAHN, Marie L. Art et Technique à la Fin du XIXe Siècle. in Annexe - Adolphe Appia. Oeuvres Complètes. Tome I. Lausanne: Société Suisse du Théâtre/L'Âge d'Homme, 1983.

BALAKIAN, Anna. O Simbolismo. São Paulo: Perspectiva, 1985.

BENTHAN, Frederick. The Art of Stage Lighting. Londres: Pitman Pub, s/d.

BERTHOLD, Margot. História Mundial do Teatro. São Paulo: Perspectiva, 2003.

CAMARGO, Roberto Gill. A Função Estética da Luz. Sorocaba: Fundo de Cultura, 2000.

CRAIG, Edward Gordon. Da Arte do Teatro. Arcádia, Lisboa, 1963.

DORT, Bernard. O Teatro e Sua Realidade. São Paulo: Perspectiva, 1977.

GUINSBURG, Jacó (org.). Semiologia do Teatro. São Paulo: Perspectiva,1978.

GUINSBURG, Jacó. Romantismo, Historicismo e História. In: O Romantismo. São Paulo: Perspectiva, 1985.

KELLER, Max. Light Fantastic. The Art and Design of Stage Lighting. Munique: Prestel Verlag 2006.

MOUSSINAC. Léon. História do Teatro das origens aos nossos dias. Trad. Mario Jacques. Portugal: Livraria Bertrand, s/d.

PAVIS, Patrice. A Análise dos Espetáculos. São Paulo: Perspectiva, 2003. 
PICON-VALLIN, Béatrice. A Arte do Teatro: entre tradição e Vanguarda - Meyerhold e a cena contemporânea. Org. Fátima Saadi. Rio de Janeiro: Teatro do Pequeno Gesto: Letra e Imagem, 2006.

REID, Francis. The Stage Lighting Handbook. Londres: A\&C Black, 1987.

REDONDO JR. O Teatro e sua Estética. Lisboa: Arcádia, 1964.

ROSENFELD, Anatol. O Teatro Alemão. São Paulo: Brasiliense, 1968.

ROUBINE, Jean-Jaques. A Linguagem da Encenação Teatral, 1880/1980. Rio de Janeiro: Zahar, 1996.

SARAIVA, Hamilton F. Iluminação Teatral: História, Estética e Técnica. Dissertação de Mestrado. São Paulo: ECA/USP, 1990, 2 vol.

STREADER, Tim e WILLIAMS, John A. Create Your Own Stage Lighting. New Jersey: Prentice Hall Inc., 1985.

TELLES, Gilberto Mendonça. Vanguarda Européia e Modernismo Brasileiro Petrópolis: Vozes, 2005.

WÖLFFLIN, Heinrich. Renascença e Barroco. São Paulo: Perspectiva, 1989.

ZAMORA, Juan Guerrero. História del Teatro Contemporáneo. E. Juan Flores, 4v., 1960.

\section{Catálogos}

DUSBOSCQ, Jules. Catalogue des appareils employés pour la production des phénomènes physiques au Théâtre. In: Art et Technique à la Fin du XIXe Siècle (org. Marie Bablet-Hahm). Annexe a Adolphe Appia, Oeuvres Complètes, Tome I. Lausanne: Société Suisse du Théâtre/L'Âge d'Homme, 1983.

BÄHR, Hugo, (Catálogo de 1906). In: Art et Technique à la Fin du XIXe Siècle (org. Marie Bablet-Hahm). Annexe a Adolphe Appia, Oeuvres Complètes, Tome I. Lausanne: Société Suisse du Théâtre/L'Âge d'Homme, 1983. 